\title{
The Design of The TU Service Project Monitoring System in PT. GMF Aeroasia Tbk
}

\author{
Erika Ramadhani ${ }^{1}$, Handika Irawan ${ }^{1}$ \\ ${ }^{1}$ Department of Informatics, Universitas Islam Indonesia \\ 1erika@uii.ac.id
}

\begin{abstract}
TO unit is one of the units in the GMF in the Information \& Communication Technology division, one unit is the TOB has a Self Development Application (SDA) task. At present many requests for procurement of goods are submitted to the TU service. This is certainly very influential on TU services that become less optimal and irregular. So a system design was made to monitor the TU Service project. The research method is carried out by analyzing business requirements and business cases. After analyzing the two documents, then make a blueprint containing the system description starting from the explanation of each module or feature and appearance of the system. Then make the interactive prototype as a system simulation. After going through a number of these steps, a monitoring system for the Dinas TU project was developed which could be utilized by the TU Service in project management.
\end{abstract}

Keywords: GMF Aeroasia, monitoring system, blueprint, software

\section{Introduction}

GMF Aeroasia is a technical division of Garuda Indonesia Airlines. In 1984, GMF Aeroasia was transformed into an independent Maintenance \& Engineering (M\&E) division. Then in 1998 it changed to the Strategic Business Unit (SBU-GMF) which handles all maintenance of the Garuda Indonesia fleet. Finally, in 2002, the SBU-GMF was separated from Garuda Indonesia and officially became independent on behalf of PT. Garuda Maintenance Facility Aero Asia [1]. The company's structure in 2016 consists of several directors, one of which is Information \& Communication Technology (TO). Unit TO has three divisions including ICT Strategic Planning, Architecture \& Asset Management (TOP), ICT Business System Solution (TOB), and ICT Service Delivery (TOS). One of the units, namely TOB has a duty in application development or self development application (SDA).

Currently there are many submissions of goods submitted to the Corporate Affairs (TU) service office. This will result in the service performance of the unit. The quality of TU unit services which includes project management in the process of procuring either renovation or other procurement is currently still done manually. The lack of control over project management has an impact on TU's service performance that is less optimal and not measurable. This underlies the creation of a TU project monitoring system. This system is expected to be able to monitor procurement at TU starting from the request to completion. This system can also document existing documents that are a requirement in a procurement request. These documents will be stored on an FTP server, which will allow users to upload and download the document later.

\section{Rudimentary}

There are two stages in this research method that are analyzing user requirements and system design. Analysis of user needs is done so that the system that has been created will be in accordance with what is expected by the user. While the design will begin when the user's needs are fully known. This is done to minimize the time and revision when designing the system. 


\subsection{Analysis of user requirement}

Analysis of user requirements starts with business requirements and continues with the business case. Business requirements are documents that describe the user's needs for requests made, and signed by IT users, GMs, and VPs of the users concerned. Users can discuss with TOP Unit to get an initial overview of the IT requests submitted. While the business case is a document that describes a solution that is recommended both for system solutions or infrastructure solutions [2] [3].

\subsection{Main problem}

Quality Improvement of Corporate Affairs Services (TU) which includes project management in the process of procuring a renovation or other procurement project. For now the control of project management is still done manually or in the form of hardcopy, because this process for controlling project management becomes less optimal.

The TU Service project management process or procurement from a Service that can be said as a user to the TU Service as facility management. Before entering into the procurement process, the submission is divided into two parts, first is a project that enters engineering including projects such as renovation, equipment maintenance, or other repairs that require special specifications. Then the second is the submission of general goods without the need for special specifications such as ATK or other procurement. Next is the procurement process and then the process of checking procurement items if the procurement process is general goods. Whereas if procurement is a project such as renovation, the project is regularly monitored to monitor the progress of the project to completion, as for the project monitoring process until there are several documents that must be completed either by a third party or TU's own service.

\subsection{User requirement}

Based on the main description of the problem in the TU Dinas project management process, a digitalized project management system is needed because of the many projects or procurement carried out by the TU Service. This system is an integrated application that combines the procurement process systematically from upstream to downstream resulting in a structured project management monitoring solution. These applications can help in improving work efficiency such as:

1. Standardize the submission process for renovations or general items

2. Monitoring ongoing projects at GMF through the TU Service

3. Automate the appearance of notifications and reminders for the PIC project.

4. Monitoring performance and optimizing processes that can be measured significantly.

5. Reducing the administrative burden

This system will also provide benefits in the form of saving paper usage and making work more practical, especially in project management monitoring that requires speed reporting and follow-up. When making a request, the user must upload the necessary documents to the system. Some of the document files are: Budget Approval (BA), Project Order (PO), Facility Engineering Order (FEO), Unit Estimated Price (HPS), Interoffice Request Project (PR), ATR, Strip Report, Minutes of Handover (BAST ), and Good Receive (GR).

\section{Research Methodology}

In this section we will discuss the design process of the system that will be created. Some sections will be discussed including use case diagrams, flowcharts, and design of entity relationship diagrams (ERD). 


\subsection{Use case diagram}

The use case diagram of the TU project monitoring system shown in Figure 1. Consists of 12 actors/roles who will access the system. Each role will have their respective activities tailored to the needs of the system that have been analyzed previously. This system can be used by several roles or users as follows: Staff Planner, Manager Planner, Manager Engineer, Staff Engineer, General Manager Procurement, Procurement Manager, Procurement Staff, TUK Service Manager, TUK Service Staff, GMF Service users, TU Office Secretary, and Administrator.

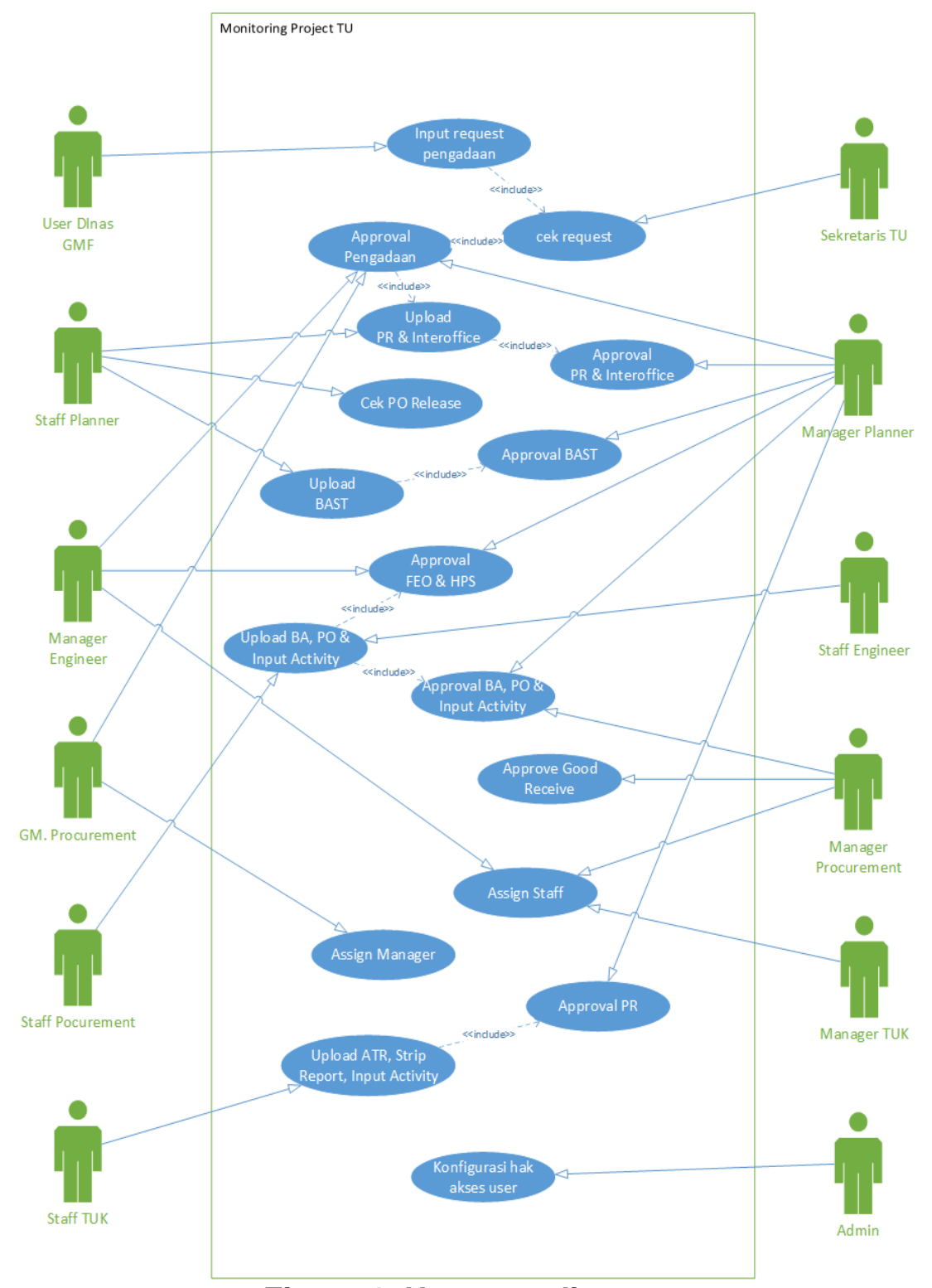

\subsection{Flowchart}

Figure 1. Use case diagram

The following is the procurement request flowchart from the beginning of the process to the end shown in Figure 2. 


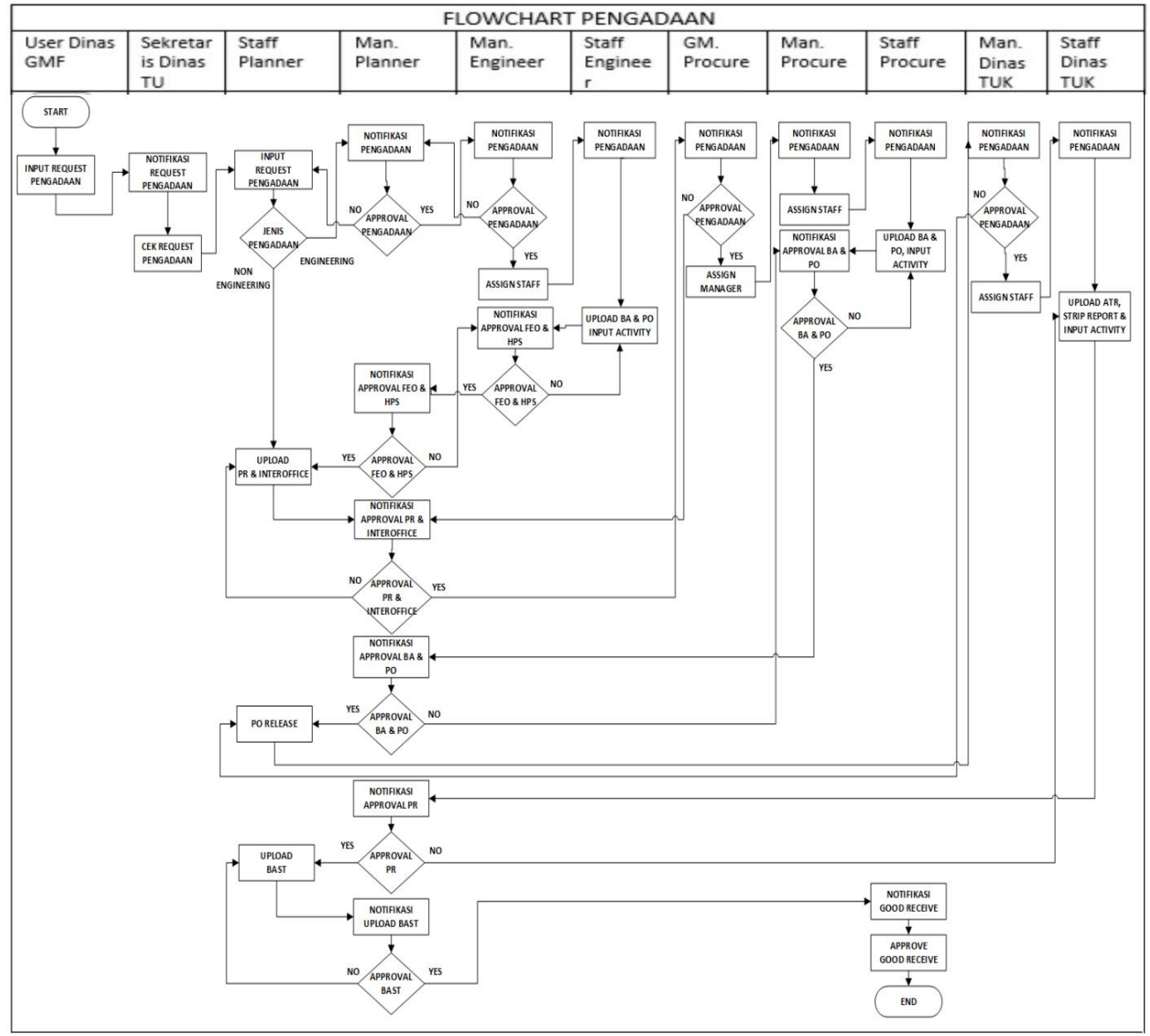

Figure 2. Flowchart of procurement

\subsection{Table Design}

This database design has been adjusted to the ERD that has been created, here is an overview of the database depicted in Figure 3.

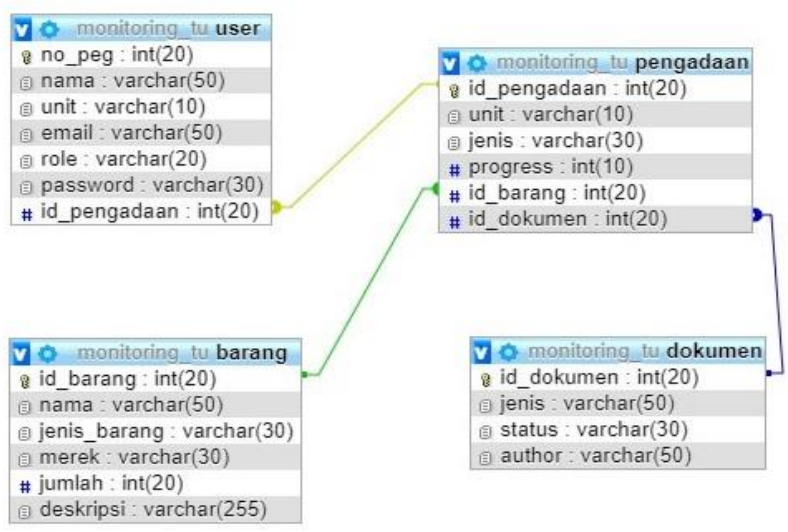

Figure 3. Design of ERD

\section{Results and Discussion}

In this monitoring system there are 5 modules, namely: (1) login module, (2) user configuration module, (3) procurement module, (4) monitoring module, and (5) help module. The procurement module is broken down into 11 modules, namely: (1) GMF service user module, (2) TU secretary module, (3) staff planner module, (4) man module. planner, (5) module man. engineer, (6) staff engineer module, (7) GM procurement module, 
(8) module man. procurement, (9) procurement staff module, (10) module man. TUK, and (11) TUK staff module.

\subsection{System Module}

This module can be used by users to monitor ongoing procurement. the user can also see the extent to which the procurement is being submitted. This module will display a list of items and a table of process weights for each unit in procurement. For procurement with this type of engineering, 3 tables of process weights will be displayed, namely engineering, planner and procurement. While for Non-Engineering types, 2 tables of process weights will be displayed, namely planner and procurement. The hope is that after monitoring, users can follow up to speed up the hampered procurement process. In this menu there is also a statistic that is displayed from the process weight table of each unit.

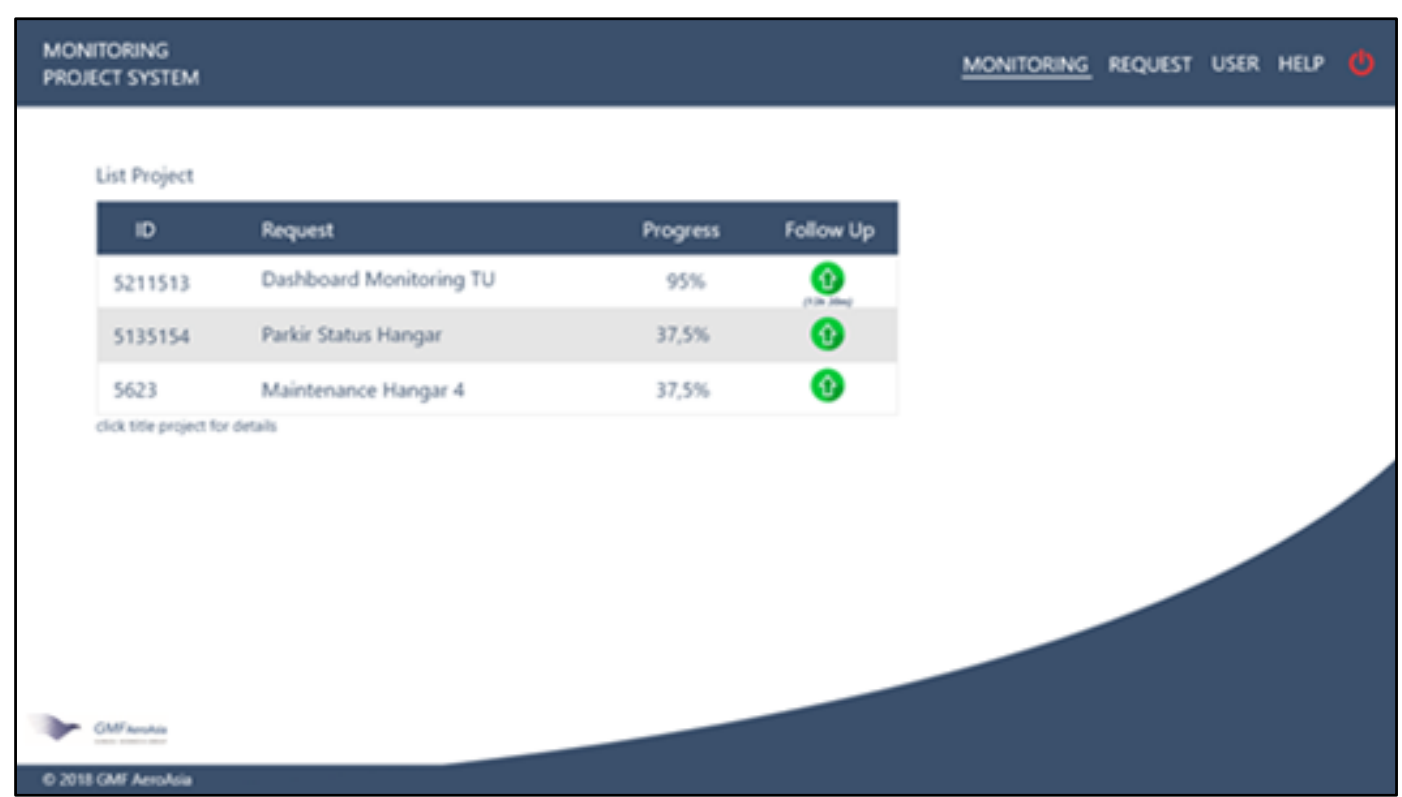

Figure 4. Procurement list page 


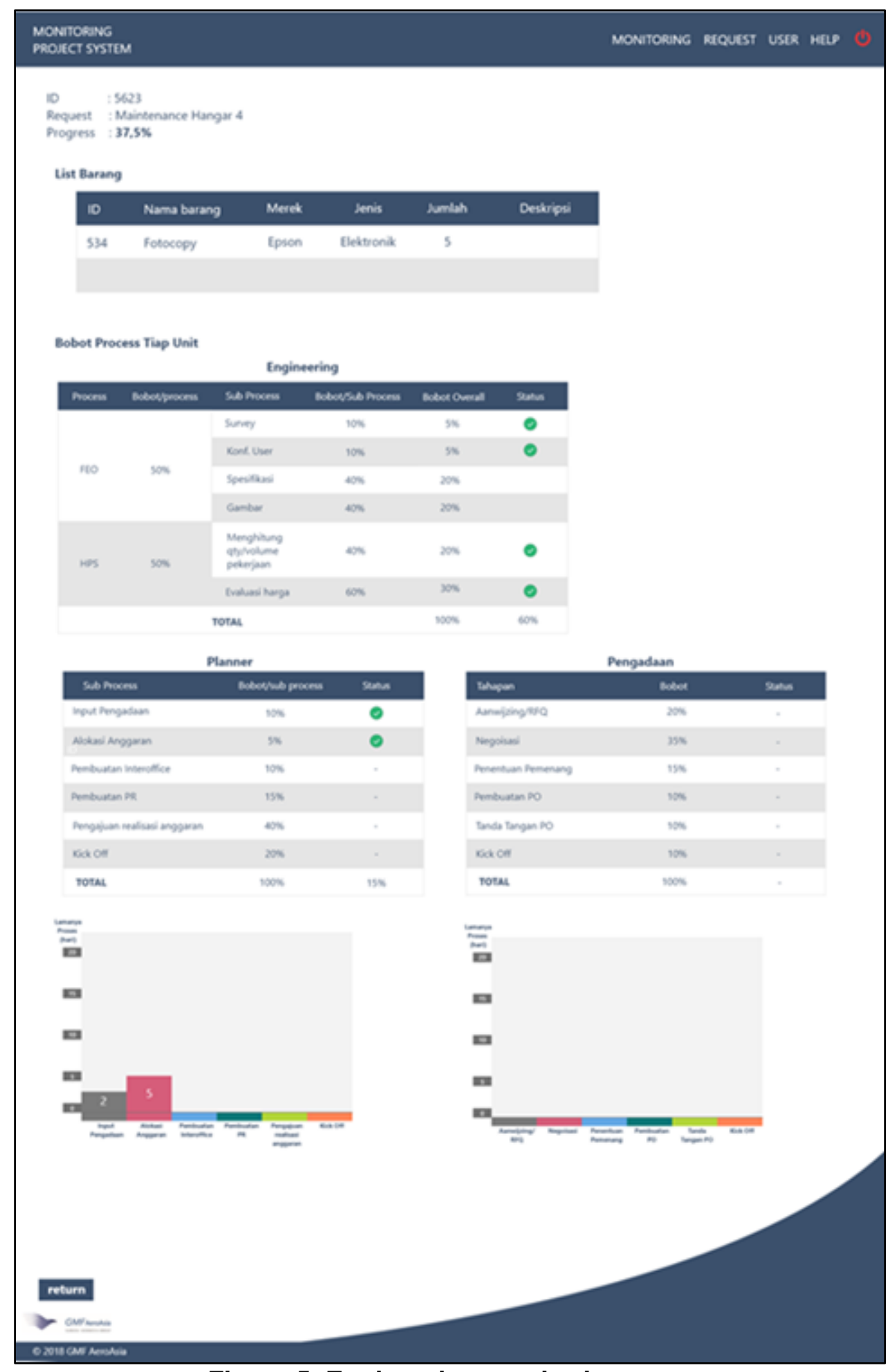

Figure 5. Engineering monitoring page 


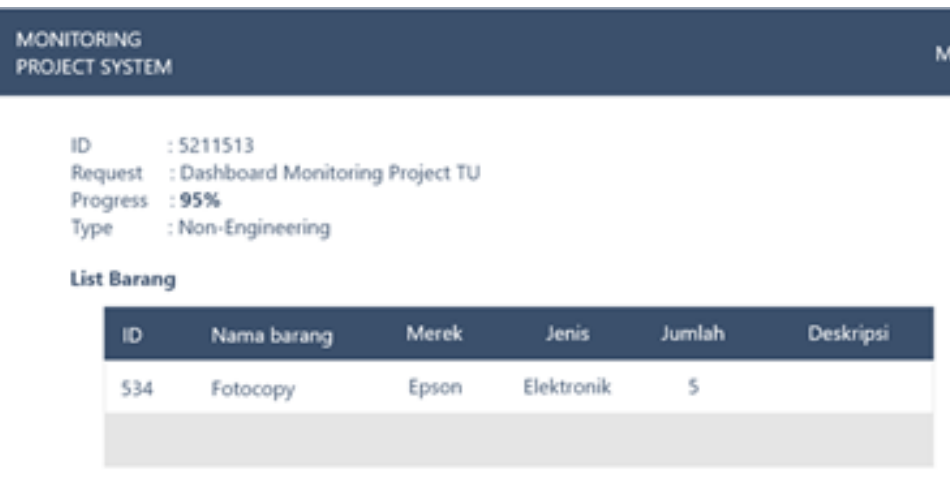

Bobot Process Tiap Unit

\begin{tabular}{|c|c|c|}
\hline \multicolumn{3}{|c|}{ Planner } \\
\hline sab Process & Babovinab process & Status \\
\hline Impun Pengadaan & $10 \%$ & 0 \\
\hline Alatemi Anggarm & sw & 0 \\
\hline Pemboutem interoffice & $10 \%$ & 0 \\
\hline Pembuacin Ph & $15 \%$ & 0 \\
\hline Pengajuan realiusti anggwan & $40 \%$ & 0 \\
\hline Kick olf & 200 & 0 \\
\hline TOTAa & $100 \%$ & $100 \mathrm{~s}$ \\
\hline
\end{tabular}

\begin{tabular}{|c|c|c|}
\hline \multicolumn{3}{|c|}{ Pengadaan } \\
\hline Thlopen & Bobot & semas \\
\hline Aanwijing wo & 2016 & 0 \\
\hline Nangoinadi & $35 \mathrm{~m}$ & $\theta$ \\
\hline Aenentuan Pemenenang & $15 \mathrm{k}$ & 0 \\
\hline Pemburtan PO & $10 \%$ & 0 \\
\hline Fanda Tangun DO & $10 \mathrm{w}$ & 0 \\
\hline Nick off & $10 \%$ & . \\
\hline Total. & $100 \mathrm{~m}$ & $900 \mathrm{~m}$ \\
\hline
\end{tabular}
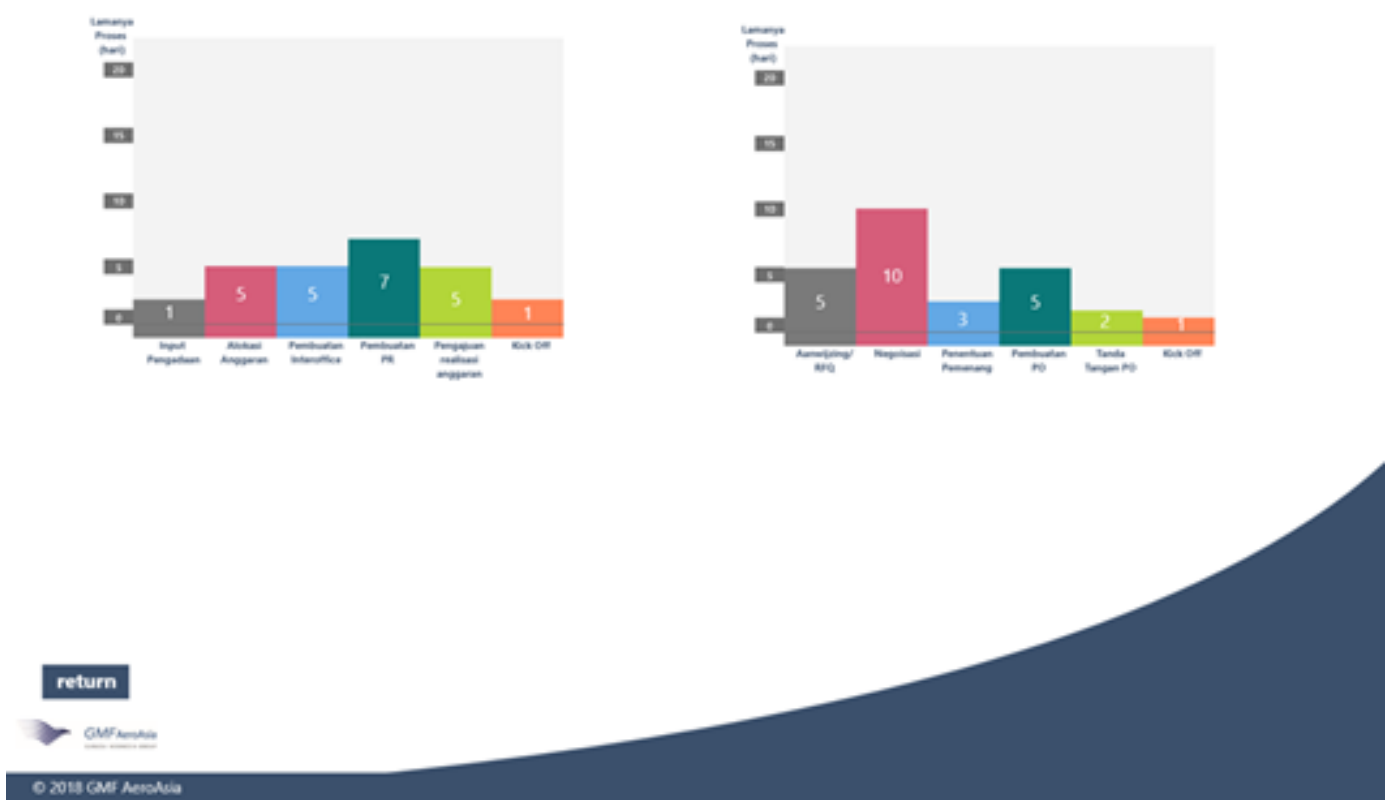

Figure 6. Non-engineering monitoring page

\section{Conclusion}

The hope is that the TU unit can run or manage projects that are running more regularly so as to improve the quality of TU services. This system can also store documents used during procurement requests given the number of documents that must be managed by the TU unit. Not forgetting also users can monitor procurement to determine the progress of the request. The user database called SOE is available on SAP companies by accessing using a PI so that the admin simply adds access rights to users who want to use this system. To remind users that the procurement process runs smoothly, the notification given will be sent directly to the user's email. 


\section{References}

[1] "About GMF", http://www.gmf-aerosia.co.id/about-gmf/, diakses 3 dan 18 November 2018.

[2] Akbar, M. Ali, "Business Requirement Dashboard Monitoring Project TU", Tangerang, PT. GMF Aeroasia Tbk. 3-10, 2018.

[3] Dameria, Josari \& Irawan, Dita, "Business Case Dashboard Monitoring Project TU". Tangerang, PT. GMF Aeroasia Tbk, 3-9, 2018.

\section{Authors}

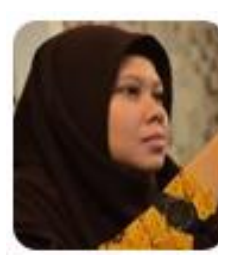

\section{$\mathbf{1}^{\text {st }}$ Author}

Erika Ramadhani

Department of Informatics

Universitas Islam Indonesia

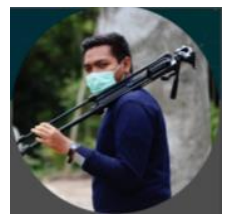

$2^{\text {nd }}$ Author

Handika Irawan

Department of Informatics

Universitas Islam Indonesia 